\title{
Binding and Activation of Small Molecules by Three-coordinate $\mathbf{C r}(\mathrm{I})$.
}

Wesley H. Monillas, Glenn P. A. Yap, Leonard A. MacAdams, and Klaus H. Theopold*

Department of Chemistry and Biochemistry, University of Delaware, Newark, DE, 19716, USA.

\section{SUPPORTING INFORMATION}


General. All manipulations of compounds were carried out using standard Schlenk, high vacuum line, and glovebox techniques under an atmosphere of $\mathrm{N}_{2}$. Solvents were purchased from Fisher Scientific, degassed, and dried by passing through activated alumina. THF- $\mathrm{d}_{8}$ and $\mathrm{C}_{6} \mathrm{D}_{6}$ was purchased from Cambridge Isotopes Laboratory and stored under vacuum over $\mathrm{Na} / \mathrm{K}$ alloy. $\mathrm{CrI}_{2}$ was prepared by a standard procedure (Hein and S. Herzog, Handbook of Preparative Inorganic. Chemistry, Academic Press, New York 1969, p. 1341 and references therein). All other reagents were purchased from Aldrich or Acros and dried using standard procedures when necessary.

${ }^{1} \mathrm{H}$ NMR spectra were taken on a Bruker DRX-400 spectrometer and were referenced to the residual protons of the solvent. FTIR spectra were taken on Mattson Alpha Centauri or Mattson Genesis Series spectrometers. UV/vis spectra were taken using a HP 8453 spectrophotometer. Mass spectra were obtained by the University of Delaware Mass Spectrometry Facility. Elemental analyses were performed by Desert Analytics. Room-temperature molar magnetic susceptibilities $\left(\chi_{\mathrm{m}}\right)$ in the solid state were determined using a Johnson Matthey magnetic susceptibility balance. They were corrected for diamagnetism using Pascal constants and converted into effective magnetic moments $\left(\mu_{\mathrm{eff}}\right)$.

Preparation of $\left[\left(2,6-{ }^{\text {i }} \mathbf{P r}_{2} \mathbf{P h}\right)_{2} \text { nacnacCr}(\boldsymbol{\mu}-\mathrm{I})\right]_{2}(\mathbf{1}):\left(2,6{ }^{\mathrm{i}} \mathrm{Pr}_{2} \mathrm{Ph}\right)_{2}$ nacnacH $(2.74 \mathrm{~g}$, $6.54 \mathrm{mmol}$ ) was dissolved in $100 \mathrm{~mL} \mathrm{Et}_{2} \mathrm{O}$ and cooled to $-30^{\circ} \mathrm{C}$. To this solution $\mathrm{n}-\mathrm{BuLi}$ $(6.54 \mathrm{mmol})$ was added drop-wise over 5 minutes and the reaction was allowed to warm to room temperature over the course of an hour. This solution was added drop-wise to a slurry of $\mathrm{CrI}_{2}(2.00 \mathrm{~g}, 6.54 \mathrm{mmol})$ in $75 \mathrm{~mL} \mathrm{Et}_{2} \mathrm{O}$ and the mixture was stirred overnight forming a brown/red solution. The solvent was removed leaving a deep red residue. Pentane was added, immediately forming a bright green solution. The solution is filtered and both flask and frit are repeatedly washed with pentane leaving behind a grey powder (LiI?). Concentration and cooling of the solution to $-30^{\circ} \mathrm{C}$ overnight yielded green crystals of 1 (3.4g, 87\% yield). ${ }^{1} \mathrm{H}-\mathrm{NMR}$ (400MHz, THF-d $\mathrm{d}_{8}$ ): 134.4 (br), 10.9 (br), 7.45 (br), 5.34 (br) ppm. IR (KBr): 3051 (w), 2958 (s), 2924 (m), 2864 (m), 1642 (w), 1526 (m), 1459 (m), 1435 (m), 1389 (s), 1314 (m), 1256 (w), 1174 (w), 1097 (w), 1064 (w), $1023(\mathrm{w}), 792(\mathrm{~m}), 756(\mathrm{w}) \mathrm{cm}^{-1}$. UV/Vis (pentane): $\lambda_{\max }(\varepsilon)=449\left(275 \mathrm{M}^{-1} \mathrm{~cm}^{-1}\right), 566$ $\left(141 \mathrm{M}^{-1} \mathrm{~cm}^{-1}\right) \mathrm{nm} . \mu_{\mathrm{eff}}(293 \mathrm{~K})=6.7(1) \mu_{\mathrm{B}}$. M. p.: $256^{\circ} \mathrm{C}(\mathrm{dec})$. Mass Spectrum $\mathrm{m} / \mathrm{z}(\%)$ : 418.4 (69) [( $\left.\left.\left.\mathrm{M}^{+} / 2\right)-\mathrm{Cr}-\mathrm{I}\right], 469.3(64)\left[\left(\mathrm{M}^{+} / 2\right)-\mathrm{I}\right)\right], 596.3(100)\left[\mathrm{M}^{+} / 2\right]$. Anal. Calcd. for $\mathrm{C}_{58} \mathrm{H}_{82} \mathrm{~N}_{4} \mathrm{Cr}_{2}$ : C, 58.39; H, 6.93; N, 4.70. Found: C, 58.30; H, 6.76; N, 4.72.

Preparation of $\left[\left(2,6-{ }^{\text {i }} \mathbf{P r}_{2} \mathbf{P h}\right)_{2}\right.$ nacnacCr $]\left(\boldsymbol{\mu}_{\mathbf{2}}-\boldsymbol{\eta}^{\mathbf{2}}: \boldsymbol{\eta}^{\mathbf{2}}-\mathbf{N}_{\mathbf{2}}\right)(\mathbf{2}):\left[\left(2,6-{ }^{\mathrm{i}} \mathrm{Pr}_{2} \mathrm{Ph}\right)_{2} \operatorname{nacnacCr}(\boldsymbol{\mu}-\mathrm{I})\right]_{2}$ $(1.00 \mathrm{~g}, 0.838 \mathrm{mmol})$ and $\mathrm{Mg}$ turnings $(0.500 \mathrm{~g}, 20.6 \mathrm{mmol})$ were placed in an ampoule with a stir bar and attached to a vacuum manifold. Approximately $15 \mathrm{~mL}$ of pure, dry THF was vacuum transferred over, followed by backfilling to $1 \mathrm{~atm}$ with dry $\mathrm{N}_{2}$. The solution was stirred for 24 hours, during which time its color changed from green to brown. After the ampoule was brought back into the drybox the THF was removed and the residue extracted with pentane. Concentration of the filtrate and cooling to $-30^{\circ} \mathrm{C}$ yielded brown crystals of $2\left(0.545 \mathrm{~g}, 67 \%\right.$ yield). ${ }^{1} \mathrm{H}-\mathrm{NMR}\left(400 \mathrm{MHz}, \mathrm{THF}-\mathrm{d}_{8}\right): 60.7$ (br), 7.94 (br), 4.78 (br), -1.99 (br) ppm. IR (KBr): 3055 (w), 2957 (s), 2923 (m), 2865 (m), 1524 (s), 1458 (s), 1435 (s), 1395 (s), 1316 (s), 1258 (m), 1176 (w), 1100 (w), 1024 (w), 
$935(\mathrm{w}), 851(\mathrm{w}), 794(\mathrm{~m}), 757(\mathrm{~m}) \mathrm{cm}^{-1}$. UV/Vis (pentane): $\lambda_{\max }(\varepsilon)=486\left(625 \mathrm{M}^{-1} \mathrm{~cm}^{-}\right.$ $\left.{ }^{1}\right), 569\left(440 \mathrm{M}^{-1} \mathrm{~cm}^{-1}\right), 656\left(260 \mathrm{M}^{-1} \mathrm{~cm}^{-1}\right) \mathrm{nm} . \mu_{\mathrm{eff}}(293 \mathrm{~K})=3.9(1) \mu_{\mathrm{B}}$. M. p.: $220^{\circ} \mathrm{C}(\mathrm{dec})$. Mass Spectrum m/z (\%): 403.3 (16) [( $\left.\left.\mathrm{M}^{+} / 2\right)-\mathrm{Cr}_{-} \mathrm{CH}_{3}\right], 465.2(100)\left[\left(\mathrm{M}^{+} / 2\right)-\mathrm{N}-3 \mathrm{H}\right], 483.2$ (40) $\left[\mathrm{M}^{+} / 2\right]$. Anal. Calcd. for $\mathrm{C}_{58} \mathrm{H}_{82} \mathrm{~N}_{6} \mathrm{Cr}_{2} \bullet \mathrm{C}_{5} \mathrm{H}_{12}: \mathrm{C}, 72.79 ; \mathrm{H}, 9.12 ; \mathrm{N}, 8.08$. Found: $\mathrm{C}$, 72.22; H, 8.13; N, 7.90.

Preparation of $\left[\left(2,6-{ }^{\mathrm{i}} \mathrm{Pr}_{2} \mathrm{Ph}\right)_{2} \text { nacnacCr }\right]_{2}(\mathrm{CO})\left(\mu-\eta^{1}: \eta^{1}-\mathrm{CO}\right)_{2}(3):[(2,6-$ $\left.{ }^{i} \mathrm{Pr}_{2} \mathrm{Ph}\right)_{2}$ nacnacCr $]_{2}\left(\mu_{2}-\eta^{2}: \eta^{2}-\mathrm{N}_{2}\right)(0.250 \mathrm{~g}, 0.258 \mathrm{mmol})$ was placed in an ampoule with a stir bar and $15 \mathrm{~mL}$ pentane and attached to a vacuum manifold. Three freeze-pump-thaw cycles were performed followed by addition of $1 \mathrm{~atm} C O$. The solution was stirred for 4 hours during which time the colored changed from brown to deep green. The $\mathrm{CO}$ was removed and the ampoule brought back into the drybox, where the solution was filtered, concentrated and cooled $-30^{\circ} \mathrm{C}$. Green crystals of $\mathbf{3}$ were collected $(0.200 \mathrm{~g}, 76 \%)$. ${ }^{1} \mathrm{H}$ NMR (400MHz, THF-d d $_{\text {) }} 118.9$ (br), 10.0 (br), 8.00 (br), 5.53 (br), 3.12 (br) ppm. IR (KBr): 3054 (w), 2958 (s), 2923 (m), 2865 (m), 1922 (vs), 1882 (w), $1795(\mathrm{w}), 1785(\mathrm{w})$, 1698 (vs), 1573 (s), 1528 (m), 1460 (w), 1436 (m), 1386 (s), 1315 (m), 1256 (w), 1173 $(\mathrm{w}), 1100(\mathrm{w}), 1054(\mathrm{w}), 1025(\mathrm{w}), 793(\mathrm{w}), 755(\mathrm{w}) \mathrm{cm}^{-1}$. UV/Vis (pentane): $\lambda_{\max }(\varepsilon)=$ $454\left(1625 \mathrm{M}^{-1} \mathrm{~cm}^{-1}\right), 585\left(319 \mathrm{M}^{-1} \mathrm{~cm}^{-1}\right)$ nm. $\mu_{\text {eff }}(293 \mathrm{~K})=4.8(1) \mu_{\mathrm{B}}$. M. p.: $304^{\circ} \mathrm{C}(\mathrm{dec})$. Mass Spectrum m/z (\%): 202.1 (100) [( $\left.\left.\mathrm{M}^{+}-3 \mathrm{CO} / 2\right)-\mathrm{Cr}-\left(2,6-{ }^{\mathrm{i}} \mathrm{Pr}_{2} \mathrm{Ph}\right)-\mathrm{C}_{2} \mathrm{H}_{4} \mathrm{~N}\right], 418.2$ (8) [(M+3 $\left.\left.\mathrm{M}^{+} 3 \mathrm{CO}\right) / 2-\mathrm{Cr}\right]$. Anal. Calcd. for $\mathrm{C}_{61} \mathrm{H}_{82} \mathrm{~N}_{4} \mathrm{Cr}_{2} \mathrm{O}_{3}: \mathrm{C}, 71.59 ; \mathrm{H}, 8.08 ; \mathrm{N}$ 5.48. Found: $\mathrm{C}$, $70.99 ; \mathrm{H}, 8.08 ; \mathrm{N}, 5.55$.

Preparation of $\left[\left(2,6-{ }^{i} \mathbf{P r}_{2} \mathbf{P h}\right)_{2}\right.$ nacnacCr $]\left(\mu_{2}-\eta^{2:} \eta^{2}-\mathbf{C}_{2} \mathbf{H}_{4}\right)(4):[(2,6-$

$\left.{ }^{\mathrm{i}} \mathrm{Pr}_{2} \mathrm{Ph}\right)_{2}$ nacnacCr $]_{2}\left(\mu_{2}-\eta^{2:} \eta^{2}-\mathrm{N}_{2}\right)(0.060 \mathrm{~g}, 0.062 \mathrm{~mol})$ was placed in an ampoule with $10 \mathrm{~mL}$ pentane. The ampoule was attached to a vacuum manifold, three freeze-pump-thaw cycles were performed, and then 1atm of dry ethylene was admitted to the ampoule. The reaction was allowed to stir for 48-72hrs, after which time the remaining ethylene was removed and the ampoule was returned to the drybox. The solvent was removed and the residue extracted with pentane. Concentration and cooling to $-30^{\circ} \mathrm{C}$ yielded brown crystals of 4 (0.038 g, 56\% yield). ${ }^{1} \mathrm{H}$ NMR (400MHz, THF-d $\left.{ }_{8}\right): 55.5$ (br), 7.82 (br), 4.42 (br), 2.99 (br), -2.1 (br) ppm. IR (KBr): 3058 (w), 2960 (s), 2925 (s), 2867 (m), 1549 (s), 1528 (s), 1458 (s), 1436 (s), 1400 (s), 1317 (m), 1260 (m), 1176 (w), 1100 (m), 1057 (w), $1023(\mathrm{~m}), 797(\mathrm{~s}), 760(\mathrm{w}) \mathrm{cm}^{-1}$. UV/Vis (pentane): $\lambda_{\max }(\varepsilon)=619\left(290 \mathrm{M}^{-1} \mathrm{~cm}^{-1}\right) \mathrm{nm} . \mu_{\text {eff }}$ $(293 \mathrm{~K})=4.2(1) \mu_{\mathrm{B}}$. M. p.: $268^{\circ} \mathrm{C}(\mathrm{dec})$. Mass Spectrum m/z (\%): $418.4(8)\left[\left(\mathrm{M}^{+}-\right.\right.$ $\left.\left.\mathrm{C}_{2} \mathrm{H}_{4}\right) / 2-\mathrm{Cr}\right], 465.3(100)\left[\left(\mathrm{M}^{+}-\mathrm{C}_{2} \mathrm{H}_{4}\right) / 2-\mathrm{Cr}-4 \mathrm{H}\right]$. Despite repeated attempts, this compound did not analyze satisfactorily.

Preparation of (2,6- $\left.{ }^{\mathrm{i}} \mathbf{P r}_{2} \mathbf{P h}\right)_{2}$ nacnacCr$(\mathbf{O})_{2}(5):\left[\left(2,6-{ }^{\mathrm{i}} \mathrm{Pr}{ }_{2} \mathrm{Ph}\right)_{2} \text { nacnacCr }\right]_{2}\left(\mu_{2}-\eta^{2}: \eta^{2}-\mathrm{N}_{2}\right)$ $(0.100 \mathrm{~g}, 0.104 \mathrm{mmol})$ was placed in an ampoule with a stir bar and $15 \mathrm{~mL}$ pentane and attached to a vacuum manifold. Three freeze-pump-thaw cycles were performed followed by addition of 1 atm $\mathrm{O}_{2}$. The solution was stirred for 6 hours during which time the colored changed from brown to deep green. The $\mathrm{O}_{2}$ was removed and the ampoule brought back into the drybox, where the solution was filtered, concentrated and cooled to $30^{\circ} \mathrm{C}$ to yield dark brown crystals of $5(0.084 \mathrm{~g}, 81 \%)$. ${ }^{1} \mathrm{H} \mathrm{NMR}\left(250 \mathrm{MHz}, \mathrm{C}_{6} \mathrm{D}_{6}\right): 9.5$ $(6 \mathrm{H}) ; 7.1(6 \mathrm{H}) ; 4.9$ (vb, 4H); $1.3(24 \mathrm{H})$ ppm. IR (KBr): $3059(\mathrm{w}), 2986(\mathrm{~s}), 2929(\mathrm{~m})$, 2867 (m), 1530 (s), 1464 (m), 1438 (m), 1356 (s), 1318 (s), 1254 (m), 1177 (w), 1103 
(w), 1057 (w), 1024 (w), 966 (s), 933 (s), 800 (s), 759 (m) cm $\mathrm{cm}^{-1} \cdot \mu_{\text {eff }}=1.8$ (1) $\mu_{\mathrm{B}}(294 \mathrm{~K})$.

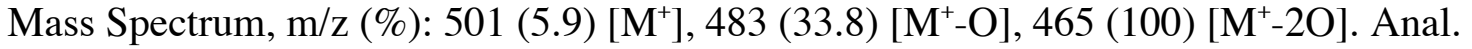
Calc'd. for $\mathrm{C}_{29} \mathrm{H}_{41} \mathrm{~N}_{2} \mathrm{O}_{2} \mathrm{Cr}_{1}$ : C, 69.43; H, 8.24; N, 5.42. Found: C, 69.60; H, 7.90; N, 5.36.

Preparation of $\left[\left(2,6-{ }^{\mathrm{i}} \mathrm{Pr}_{2} \mathbf{P h}\right)_{2} \text { nacnacCr }\right]_{2}(\boldsymbol{\mu}-\mathbf{N P h})_{2}(6):\left[\left(2,6-{ }^{\mathrm{i}} \mathrm{Pr}_{2} \mathrm{Ph}\right)_{2} \text { nacnacCr }\right]_{2}\left(\mu_{2^{-}}\right.$ $\left.\eta^{2:} \eta^{2}-\mathrm{N}_{2}\right)(0.050 \mathrm{~g}, 0.0515 \mathrm{mmol})$ was dissolved in $10 \mathrm{~mL}$ THF. Azobenzene $(0.094 \mathrm{~g}$, $0.0515 \mathrm{mmol}$ ) was added and the solution was stirred for 4 hours after which time the solvent was removed and the product was extracted with THF. Concentration and cooling of the solution yielded black crystals of 6. (0.028 g, $50 \%$ yield). ${ }^{1} \mathrm{H} \mathrm{NMR}$ (400MHz, THF-d s) 93.8 (br), 10.9 (br), 9.44 (br), 2.55 (br), -0.58 (br), -50.3 (br) ppm. IR (KBr): 2957 (s), $2925(\mathrm{~s}), 2866(\mathrm{w}), 1661(\mathrm{w}), 1653(\mathrm{~m}), 1635(\mathrm{w}), 1577(\mathrm{w}), 1557$ (m), 1539 (s), 1521 (m), 1507 (m), 1472 (s), 1457 (s), 1435 (m), 1382 (s), 1313 (w), 1277 (w), 1249 (s), $1170(\mathrm{w}), 1098(\mathrm{~m}), 1058$ (w), $1024(\mathrm{~m}), 796(\mathrm{~m}) \mathrm{cm}^{-1}$. UV/Vis (pentane): $\lambda_{\text {max }}(\varepsilon)=355\left(8720 \mathrm{M}^{-1} \mathrm{~cm}^{-1}\right), 416\left(3789 \mathrm{M}^{-1} \mathrm{~cm}^{-1}\right), 537\left(1630 \mathrm{M}^{-1} \mathrm{~cm}^{-1}\right), 658\left(1261 \mathrm{M}^{-1} \mathrm{~cm}\right.$ $\left.{ }^{1}\right) \mathrm{nm} . \mu_{\text {eff }}(293 \mathrm{~K})=2.6(1) \mu_{\mathrm{B}}$. M. p.: $239^{\circ} \mathrm{C}(\mathrm{dec})$. Mass Spectrum m/z (\%): 1120.8 (10) $[\mathrm{M}+], 560.2(100)\left[(\mathrm{M}+/ 2]\right.$. Anal. Calcd. for $\mathrm{C}_{70} \mathrm{H}_{92} \mathrm{~N}_{6} \mathrm{Cr}_{2}$ : C, 74.96; H, 8.27; N, 7.50. Found: C, 74.79; H, 7.98; N, 7.08.

Single crystal X-ray diffraction studies. Crystals were selected and mounted on glass fibers with viscous oil and cooled to the data collection temperatures, $-73^{\circ} \mathrm{C}$ for $2,-100^{\circ} \mathrm{C}$ for $5,-103^{\circ} \mathrm{C}$ for 4 , and $-153^{\circ} \mathrm{C}$ for 3 and 6 . Diffraction data were collected on a BrukerAXS APEX CCD diffractometer. All data-sets were treated with SADABS absorption corrections. Unit-cell parameters were determined by sampling three different sections of the Ewald sphere. Despite repeated attempts, 5 consistently yielded small, multiple, weakly diffracting, needle crystals, which yielded poor coverage, low resolution diffraction data. The data reported herein represent the best effort. The systematic absences in the diffraction data were consistent for space groups $C c$ and $C 2 / c$ for $\mathbf{6}, C m$ and $C 2 / m$ for 2 and, uniquely, for $P 2_{1} / n$ for $\mathbf{3}, \mathbf{4}$ and 5. Structural solution in the centrosymmetric space group options yielded chemically reasonable and computationally stable results of refinement. The data for $\mathbf{3}$ and $\mathbf{6}$ were treated with Squeeze (Spek, A.L. (2003), J.Appl.Cryst. 36, 7-13) to model as diffused contributions the severely disordered solvent molecules. Two molecules of pentane solvent per compound molecule were located disordered at a mirror in $\mathbf{2}$. The compound molecule is located at a mirror and two-fold axis in $\mathbf{2}$. The compound molecule is located at an inversion center in $\mathbf{4}$. The compound molecule in $\mathbf{6}$ is located at a two-fold axis with each symmetry unique, halfmolecule disordered with a refined site occupancy ratio of 82/18. All nonhydrogen atoms were refined with anisotropic displacement parameters. Hydrogen atoms $\mathrm{H} 1$ and $\mathrm{H} 2$ in 4 were located from the difference map and positionally refined with $\mathrm{C}-\mathrm{H}$ distances restrained to be similar and with $0.20 U_{e q}$ of $\mathrm{C} 1$. All other hydrogen atoms were treated as idealized contributions. Structure factors are contained in SHELXTL 6.12 program library (G. Sheldrick, 2001; Siemens XRD, Madison, WI). 


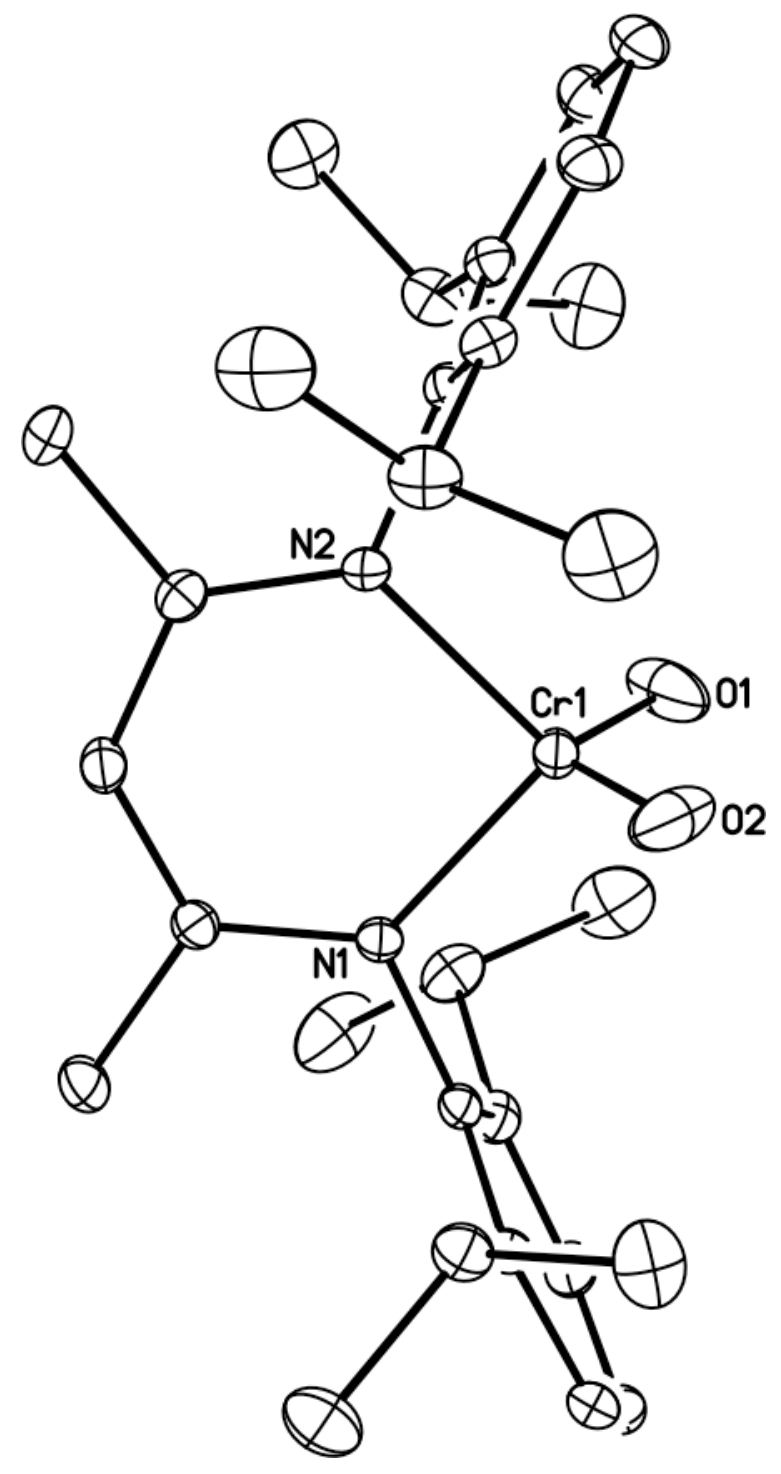

Figure S1. The molecular structure of $\left(i-\mathrm{Pr}_{2} \mathrm{Ph}\right)_{2} \operatorname{nacnacCr}(\mathrm{O})_{2}(\mathbf{5}, 30 \%$ probability ellipsoids). Selected interatomic distances $[\AA]$ and angles $\left[{ }^{\circ}\right]:$ : Cr1-O1, 1.591(4); Cr1O2, 1.600(4); O1-Cr1-O2, 118.4(3). 


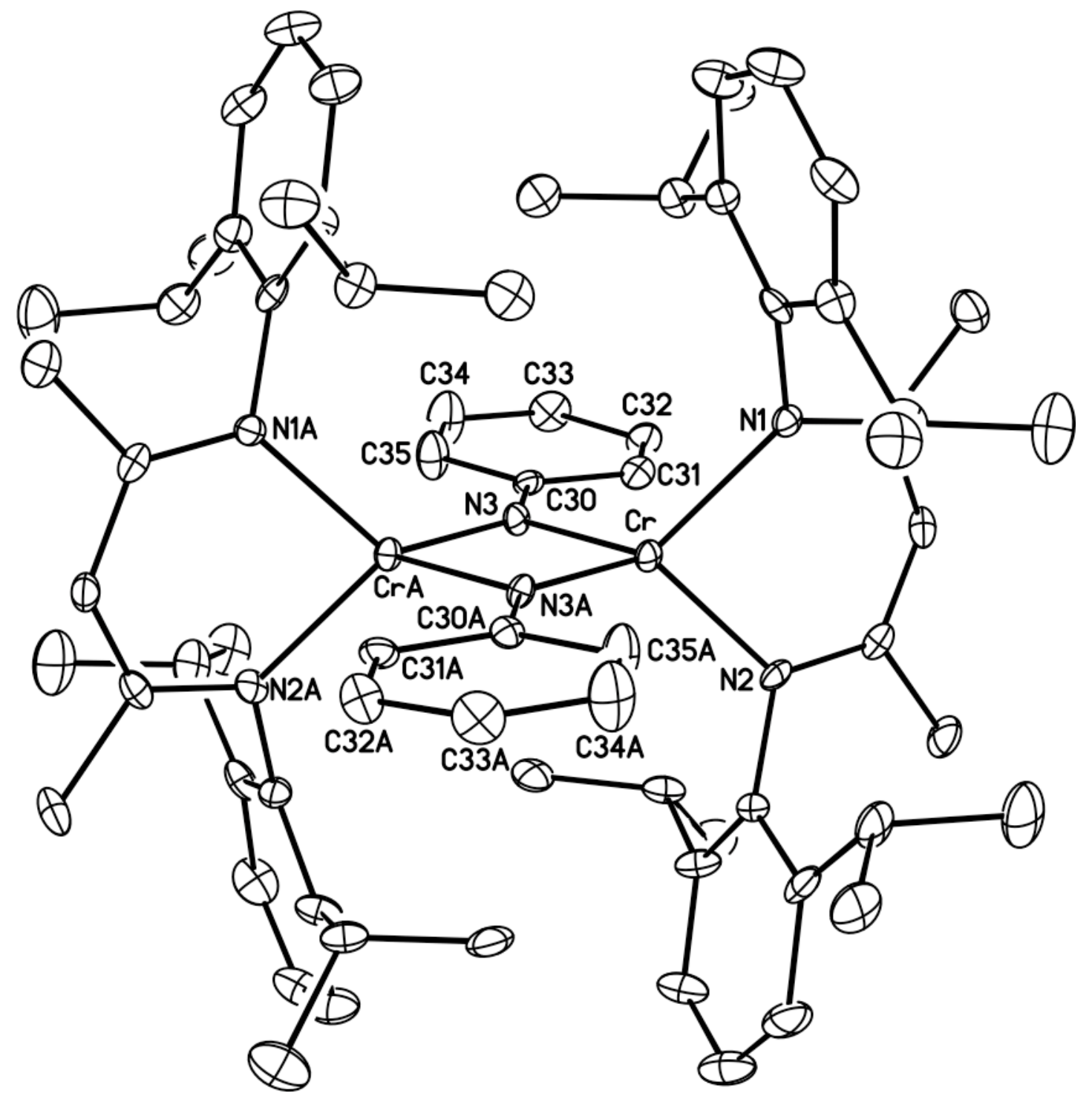

Figure S2. The molecular structure of $\left[\left(i-\mathrm{Pr}_{2} \mathrm{Ph}\right)_{2} \text { nacnacCr }\right]_{2}(\mu-\mathrm{NPh})_{2}(6,30 \%$ probability

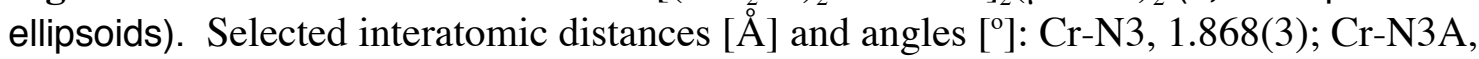
1.916(3); Cr-CrA, 2.7576(14); Cr-N3-CrA, 93.54(14). 